\title{
IMPLEMENTAÇÃO DAS BOAS PRÁTICAS DE FABRICAÇÃO EM INDÚSTRIA PROCESSADORA DE GOMA DE TAPIOCA
}

\section{IMPLEMENTATION OF GOOD MANUFACTURING PRACTICES IN THE TAPIOCA GUM PROCESSING INDUSTRY}

\author{
Aline Macedo Dantas 1,2,3,4 \\ Instituto Federal do Rio Grande do Norte, Campus Currais Novos - RN, Brasil \\ https://orcid.org/0000-0001-5322-919X \\ alinedantasm@gmail.com \\ Rhennan Victor Lourenço Marques ${ }^{3,4}$ \\ Universidade Federal da Paraíba, Departamento de Engenharia de Alimentos, João Pessoa \\ $-\mathrm{PB}$, Brasil \\ https://orcid.org/0000-0002-9995-7317 \\ rhennan.victor@gmail.com \\ Profa. Orientadora Mestra Marizania Sena Pereira ${ }^{3,5}$ \\ Instituto Federal do Rio Grande do Norte, Campus Currais Novos - RN, Brasil \\ https://orcid.org/0000-0002-0820-2163 \\ marizania.sena@ifrn.edu.br \\ ${ }^{1}$ Administração do Projeto, \\ 2 Análise Formal, Conceituação, Curadoria de Dados \\ ${ }^{3}$ Escrita - Revisão e Edição, \\ ${ }^{4}$ Investigação, Metodologia \\ ${ }^{5}$ Supervisão, Validação e Visualização
}

\begin{abstract}
RESUMO
A indústria de alimentos tem como obrigatoriedade a implementação das Boas Práticas de Fabricação (BPF), que são medidas que proporcionam a obtenção de um alimento seguro. Desta forma, o objetivo deste trabalho foi a implementação das BPF em uma indústria processadora de goma de tapioca. Primeiramente foi realizado um diagnóstico da empresa aplicando um checklist com itens exigidos pela legislação brasileira, e após as orientações a respeito das BPF outro checklist foi aplicado para verificar 0 resultado do trabalho desenvolvido. No primeiro diagnóstico, a empresa tinha
\end{abstract}

$28,66 \%$ de itens conformes, após as orientações sobre as BPF foi possível atingir $81,1 \%$ de itens conformes. Apesar de ainda existirem pontos a melhorar, pode-se findar que 0 objetivo de implementar as BPF foi concluído, o que vai proporcionar a indústria de goma, a obtenção de um alimento de qualidade, mais seguro e com riscos de contaminação reduzidos, contribuindo assim com a manutenção da saúde dos consumidores deste produto.

Palavras-chave: Checklist. Qualidade. Segurança de alimentos. 


\section{ABSTRACT}

The food industry is obliged to implement Good Manufacturing Practices (GMP), which are measures for providing safe food. Thus, the aim of this research the implementation of GMP in a tapioca starch processing industry, providing higher food safety, quality of products, competitive advantage, and higher productivity. First of all, a diagnosis of the company was made, applying a checklist with items required by Brazilian legislation, and after the GMP guidelines, another checklist was applied to verify the result of the work developed. In the first diagnosis, the company had $28.66 \%$ of items compliant, following the GMP guidelines, it was possible to reach $81.1 \%$ of items compliant. Although there are still points to improve, it can be concluded that the main goal of implementing GMP was completed; It will provide the tapioca starch industry with quality food, safer, and contamination risks reduced, thus, contributing to the preservation of the health of the consumers of this product.

Keywords: Checklist. Quality. Food Safety.

\section{INTRODUÇÃO}

A preocupação pela qualidade $\mathrm{e}$ segurança dos alimentos é mundial e deve ser tratada com seriedade por todas as unidades produtoras, pois a manipulação de alimentos está diretamente relacionada com a saúde pública. Desta forma, medidas que proporcionem alimentos seguros devem ser prioridade em toda indústria de alimentos.

Essas medidas vêm sendo adotadas também visando vantagem competitiva e melhoria contínua, além de ser uma exigência dos consumidores.
Sendo assim a busca crescente por qualidade se torna um diferencial (BUZINARO; GASPAROTTO, 2019).

A principal maneira de alcançar a qualidade referente a segurança do alimento é a adoção das Boas Práticas de Fabricação (BPF). Tais medidas englobam todas as etapas do processamento e no Brasil é uma obrigatoriedade legal de toda indústria processadora de alimentos (BRASIL, 1997; BRASIL, 2002).

Para o sucesso de sua implementação, deve-se englobar todo os setores da indústria, incluindo a área administrativa e de apoio. Tais medidas visam proporcionar um ambiente de trabalho eficiente e satisfatório, além da redução de riscos e otimização da produção (PERES, 2014; SILVA; PIERRE, 2017).

As BPF não dependem apenas da sua aplicação pontual, mas é um processo contínuo que deve ser rotina dentro da unidade processadora de alimentos. Necessitando de manutenção das instalações, equipamentos e utensílios, higienização diária, além de atualização dos documentos e dos treinamentos capacitadores (BUZINARO; ASPAROTTO, 2019; GIRELLI et al., 2015)

A implementação das BPF na indústria de alimentos, requer atenção, a sua manipulação por muitas vezes ocorre de forma manual, desta forma, deve-se 
orientar adequadamente os manipuladores acerca dos procedimentos adequados a fim de evitar contaminações que possam causar prejuízos a saúde do manipulador (LOPES et al., 2020).

Diante do exposto, o objetivo do trabalho foi realizar a implementação das BPF em uma indústria processadora de goma de tapioca.

\section{METODOLOGIA}

O trabalho foi desenvolvido em uma empresa produtora de goma de tapioca peneirada, localizada na Região Metropolitana de João Pessoa - PB, com produção diária de $7.000 \mathrm{Kg}$ de goma de tapioca. Em seu quadro possui 17 colaboradores, que atuam diretamente com a manipulação do produto.

Inicialmente, para avaliação das Boas Práticas de Fabricação existentes e realização de um diagnóstico da empresa, foi utilizado o checklist proposto no Anexo
Il da RDC 275/2002 (BRASIL, 2002). Neste, foram avaliados os itens distribuídos em categorias, como edificações e instalações; equipamentos, móveis e utensílios; manipuladores; produção e transporte dos alimentos e por fim a documentação, totalizando 164 itens.

Após a obtenção do diagnóstico obtido pelo checklist, foi elaborado um plano de ação para cada item em não conformidade, trançando as ações corretivas para que o BPF fosse implementado.

\section{RESULTADOS E DISCUSSÃO}

Após a aplicação do checklist de diagnósticos, dos 164 itens avaliados segundo a RDC 275/2002 (BRASIL, 2002), 47 (28,65\%) apresentavam-se em conformidade, 101 (61,59\%) não conforme e 17 (10,36\%) não aplicáveis. Na Tabela 1 é possível observar os resultados referente aplicação dessa lista de verificação.

Tabela 1 - Resultado do checklist aplicado antes da implantação das BPF.

\begin{tabular}{cccc}
\hline Categoria avaliada & Conforme & Não conforme & Não se aplica \\
\hline & \multicolumn{3}{c}{ № de itens (percentual \%) } \\
\hline Edificações e instalações & $23(29,11)$ & $46(58,23)$ & $10(12,66)$ \\
\hline $\begin{array}{c}\text { Equipamentos, móveis e } \\
\text { utensílios }\end{array}$ & $8(38,10)$ & $11(52,38)$ & $2(9,52)$ \\
\hline Manipuladores & $6(42,86)$ & $8(57,14)$ & $1(7,14)$ \\
\hline Transporte dos alimentos & $10(30,30)$ & $19(57,58)$ & $4(12,12)$ \\
\hline Documentação & 0,00 & $17(100,00)$ & 0,00 \\
\hline Total & $47(28,66)$ & $101(61,59)$ & $17(10,37)$ \\
\hline
\end{tabular}

Compondo a categoria de documentação, a empresa não cumpria com nenhuma das exigências das BPF, essa foi a categoria com o maior número 
(100\%) de não conformidades, pois não existia Manual de Boas Práticas de Fabricação, Procedimentos Operacionais Padronizados e Registros de pontos de controle.

No que se refere as edificações e instalações, 58,23\% forma não conformes, seguido de transportes dos alimentos (57,58\%), manipuladores (57,54\%) e equipamentos móveis e utensílios (52,38\%).

Ainda referente ao checklist disponibilizado pela RDC 275/2002 (BRASIL, 2002) há uma classificação do estabelecimento de acordo com a quantidade de não conformidades encontradas durante a auditoria. A empresa avaliada ficou dentro do GRUPO 3-0 A $50 \%$ de atendimento dos itens.

Altos valores de não conformidade também foram observados por Oliveira, Silva e Carvalho (2018), ao avaliarem as BPF em indústrias de queijo coalho. Os autores enfatizaram a alta probabilidade de ocorrer eventos que prejudiquem a qualidade e a segurança do alimento, sendo imprescindível a adequação e consequente diminuição do número de não conformidades desses estabelecimentos.

Após o diagnóstico, foi realizado uma reunião com os gestores da indústria e traçado um plano de ação. Primeiramente foi verificada a necessidade do treinamento de boas práticas com todos os colaboradores, sendo essa a primeira a ação a ser realizada, pois a partir dela seria possível o esclarecimento acerca das exigências da legislação, para que as cobranças se tornassem pertinentes. Neste foram abortados conceitos básicos de microbiologia, contaminação de origem alimentar, medidas preventivas de contaminação, armazenamento adequado e higiene pessoal e superfícies.

Caminotto et al. (2020) relataram que o treinamento de colaboradores contribui para melhorar a qualidade dos alimentos, pois os funcionários se tornaram mais engajados e conscientes sobre a manipulação segura dos alimentos.

Para a adequação de itens referentes a edificações e instalações; equipamentos, móveis e utensílios e transporte de alimentos, os gestores foram orientadores sobre a medidas corretivas. Por necessitarem de investimentos, essas mudanças também demandaram um trabalho de conscientização dos gestores, para que se tornassem convencidos da sua necessidade.

$\mathrm{Na}$ categoria documentação foram elaborados os Procedimentos Operacionais Padrão (POP's), Registros de pontos de controle e por fim o Manual de Boas Práticas de Fabricação, que descrevem todos as etapas da produção e os cuidados tomados para se evitar contaminação do alimento. Para o 
preenchimento das planilhas de controle, foi designado um responsável, uma medida de se evitar possíveis esquecimentos.
O checklist também foi aplicado após a implantação das BPF (Tabela 2), onde a porcentagem de itens conformes aumentou para $81,1 \%$ e o número de não conformidades reduziu para $9,15 \%$.

Tabela 2 - Resultado do checklist aplicado após a implantação das BPF.

\begin{tabular}{cccc}
\hline Categoria avaliada & $\begin{array}{c}\text { Conforme } \\
(\%)\end{array}$ & $\begin{array}{c}\text { Não conforme } \\
(\%)\end{array}$ & $\begin{array}{c}\text { Não se aplica } \\
(\%)\end{array}$ \\
\hline Edificações e instalações & $60(75,95)$ & $\begin{array}{c}\text { № de itens (percentual \%) } \\
11(13,9)\end{array}$ & $8(10,13)$ \\
Equipamentos, móveis e & $19(90,48)$ & 0,00 & $2(9,52$ \\
utensílios & $13(92,86)$ & 0,00 & $1(7,14)$ \\
Manipuladores & $24(72,73)$ & $4(12,12)$ & $5(15,15)$ \\
Transporte dos alimentos & $17(100,00)$ & 0,00 & 0,00 \\
Documentação & $133(81,10)$ & $15(9,15)$ & $16(9,76)$ \\
Total & &
\end{tabular}

Um destaque para a categoria de documentação, que passou de 100\% de não conformidade para $100 \%$ de conformidade. Isso se deve, pois a manutenção dos itens dessa categoria demanda pouco investimento financeiro, pois dependem apenas do empenho dos colaboradores em manter a atualização dos documentos. Diferente do que ocorre nas categorias edificações e instalações, equipamentos, móveis e utensílios e transporte de alimentos, pois demanda maiores investimentos financeiros e nem sempre a empresa está preparada a isto.

Em todas as categorias avaliadas ocorrem aumento no número de conformidades, e conforme classificação proposta pela RDC 275/2002 (BRASIL, 2002), a empresa ficou no GRUPO 1 - 76 a $100 \%$ de atendimento dos itens.
Sinhorini, Oliveira e Alfaro (2015) implantaram e avaliaram as BPF em uma indústria de subprodutos de carnes, e observaram também um aumento no número de itens conformes, de $64,2 \%$ para 99\%, após o início do trabalho, e atribuíram esse aumento principalmente devido a conscientização efetiva dos manipuladores e gestores durante a execução do trabalho.

Os itens que ainda ficaram em não conformidades são referentes as edificações e instalações (13,92\%) e transporte de alimentos (12,12\%), e que por demandarem investimentos financeiros ainda não entraram no orçamento da empresa, mas que já estão inclusos em projetos futuros.

Por ser um processo que demanda continuidade, a implementação das BPF nunca deve ser decretado o seu fim, pois 
haverá sempre a demanda de adaptações, inovações e melhoria no processo (VERONEZI; CAVEIÃO, 2015).

\section{CONSIDERAÇÕES FINAIS}

A proposta de implementação das BPF na empresa de goma de tapioca alvo deste trabalho foi de grande relevância, visto o alto número de não conformidades.

Ademais, a empresa evoluiu muito em relação às BPF, com alterações na sua rotina, instalações e com a elaborações dos documentos. Apesar de ainda existirem pontos a serem melhorados, já foram realizadas as devidas orientações e um adequado investimento, a fim de serem também resolvidos.

O objetivo de implementar as BPF foi atingido, o que vai proporcionar à indústria de goma, a obtenção de um alimento com redução nos riscos de contaminação e a padronização do processo, contribuindo para a inocuidade do produto

\section{REFERÊNCIAS BIBLIOGRÁFICAS}

BRASIL. Ministério da Saúde. Portaria SVS/MS no 326, de 30 de julho de 1997. Regulamento técnico sobre as condições higiênico-sanitárias e de boas práticas de fabricação para estabelecimentos produtor e/industrializadores de alimentos. MS, Brasília, 1997.

BRASIL. Ministério da Saúde. Resolução de diretoria colegiada - RDC no 275, de 21 Revista Higiene Alimentar, v. 35 (293): e1061, 2021 ISSN 2675-0260 - DOI: 10.37585/HA2021.02implementacao de outubro de 2002. Regulamento técnico de procedimentos operacionais padronizados aplicados aos estabelecimentos produtores/industrializadores de alimentos e a lista de verificação das boas práticas de fabricação em estabelecimentos produtores/industrializadores de alimentos. MS, Brasília, 2002.

BUZINARO, D., V. C.; GASPAROTTO, A. M. S. Como a implementação das boas práticas de fabricação (BPF) auxiliam a competitividade e a qualidade em uma indústria. Interface Tecnológica, v. 16, n. 2, 2019.

PERES, L., A. Boas Práticas de Fabricação em matadouro-frigorífico de bovinos. 2014. 33f. Trabalho de conclusão de curso (Especialização em Produção Tecnologia e Higiene de Alimentos de :Origem Animal). Faculdade de Veterinária, Universidade Federal do Rio Grande do Sul, Porto Alegre, 2014.

SINHORINI, M., R.; OLIVEIRA, L., S. de; ALFARO, A. de T. Implantação e avaliação das Boas Práticas de Fabricação - BPF: estudo de caso. Revista Instituto Adolfo Lutz, v. 74, n. 2, 140-4, 2015.

VERONEZI, C.; CAVEIÃO, C. A importância da implantação das boas práticas de fabricação na indústria de alimentos. Revista Saúde e Desenvolvimento, v. 8, n. 4, p. 90-103, 2015.

LOPES, L. C.; PRESTES, C. F.; MENDES, L. G.; PAULA, M. de; AUGUSTOS, M. M. M.; CRUZ, W. S. da. Boas práticas de fabricação: treinamento aplicado aos manipuladores de alimentos de restaurante universitário. Brazilian Journal of Developmente., v. 6, n. 7, p. 49282-49289, 2020.

GIRELLI, A.; KOLCHINSKI, E. M.; BIONDO, E.; SANT1ANNA, V. Análise da aplicação das boas práticas de fabricação 
nas agroindústrias familiares do arranjo produtivo local do vale do taquari. Revista Eletrônica Científica da UERGS. v. 1, n. 1, p. 50-57, 2015.

SILVA, V. F.; PIERRE, F. C. Análise das boas práticas de fabricação da indústria leiteira do interior do estado de São Paulo. Tekhne e Logos, v. 8, n. 1, 2017.

CAMINOTTO, E. de L.; MARTINS, C. E. N.; VARELA, D. H.; CAMARGO, K. S. de. Impactos do curso de capacitação para os manipuladores de produtos de origem animal. Brazilian Journal of Develoment, v. 6, n. 9 , p. $64044-64052,2020$.

OLIVEIRA, C. P de; SILVA, A. C. de; CARVALHO, M. das G. X. de C. Diagnóstico das condições higienicossanitárias do processo de fabricação de queijo de coalho no sertão paraibano.Higiene Alimentar, v. 32, n. 284/285, p. 66-71, 2018. 